Hewavitharana, T., Nanayakkara, S. and Perera, S., 2019. Blockchain as a project management platform. In: Sandanayake, Y.G., Gunatilake, S. and Waidyasekara, A. (eds). Proceedings of the $8^{\text {th }}$ World Construction Symposium, Colombo, Sri Lanka, 8-10 November 2019, pp. 137-146. DOI: doi.org/10.31705/WCS.2019.14. Available at: https://2019.ciobwcs.com/papers

\title{
BLOCKCHAIN AS A PROJECT MANAGEMENT PLATFORM
}

\author{
Thathsarani Hewavitharana ${ }^{1}$, Samudaya Nanayakkara ${ }^{2}$ and Srinath Perera ${ }^{3}$
}

\begin{abstract}
The construction industry will continue to be a key driver of economic growth for any country. It is one of the biggest industries in the world which contributes heavily to the economic development of a country. However, the productivity and the effectiveness of the industry have often been called into a question. Therefore, a number of different modelling tools and software have introduced to upgrade the standards of the construction industry. This review seeks to identify how blockchain can address the project management perspectives of the construction industry with respect to the guidelines mentioned in the Project Management Body of Knowledge. Five major criterions namely purchase management, contract management, asset and inventory management, finance management and subcontractor management were selected for the analysis using the PMBOK guidelines. For that, literature review using articles in ScienceDirect which appeared the context "blockchain in construction", "blockchain and project management", "application of blockchain" were referred. It is identified that the blockchain technology can assist financial management without involving third parties, subcontractor management by linking derivable and payment schemes, contract administration by using smart contracts, inventory and asset management by tracking and tracing material movements and purchase management by linking key stakeholders in supply chains.
\end{abstract}

Keywords: Blockchain; Construction Industry; Project Management; Smart Contract

\section{INTRODUCTION}

The construction industry has been dared for a long time to enhance its efficiency, productivity and to embrace opportunities coming along with disruptive technologies. However, with the fourth industrial revolution, the construction industry had to move forward with digital technologies such as the Internet of Things (IoT), 3D Printing, Building Information Modelling (BIM) and others. The blockchain is the latest technology which is embarked upon the digitalisation of the construction industry, and it has created a new era for the utilisation of the internet. That is mainly because the information on the blockchain is updating continuously and shared among members. It does not locate in one place and opens for the public with the ability to verify in public blockchain, and private blockchain networks facilitate for handling sensitive data. Therefore, it empowers companies to do business with one another more easily using shared business processes encoded within a common platform.

\footnotetext{
${ }^{1}$ University of Moratuwa, Sri Lanka, sachindrahewavitharana@gmail.com

${ }^{2}$ Western Sydney University, Australia, s.nanayakkara@westernsydney.edu.au

${ }^{3}$ Western Sydney University, Australia, srinath.perera@westernsydney.edu.au
} 
The manufacturing industry is trying to utilise blockchain for their operations primarily in the supply chain management. It provides a transparent mechanism in the transaction process of goods, data and financial resources. Healthcare sector and Banking sectors are two other industries who are trying to use blockchain technologies. Further, the legal sector is focusing blockchain for smart contracts as well as future election systems will be deviated from traditional procedures and will move with blockchain technologies to improve trust and transparency.

There are many advantages of blockchain technology. It is used to make payments without show and to improve trust. Smart contracts are using the technology to reduce delays, outside interferences and to reduce the documentations in contractual decisionmaking processes. Further distributed data storage mechanism will mitigate some data risk. Also, with the blockchain has a capability to easily to track and monitor digital identities because of the authorisation systems adopted in the blockchain. Subsequently, blockchain can work as a low-cost notary system which can reduce the expenses. It has the ability to communicate with distributed IoT devices for extracting information and share with member nodes. Therefore, blockchain technology can be identified as a bridge to the digital future.

However, there are some disadvantages in blockchain technology. Some blockchain technologies use excessive energy consumption processes such as mining or introducing new data block to ledger. Blockchain technology does not allow to overwrite or change the data. So, it will limit the flexibility of correction if wrong data was fed. As a novel and distributed technology, it is challenging to develop and implement blockchain-based solutions when compared with traditional software solutions.

In spite of the disadvantages of blockchain technology, many industries have gained the advantages out of it, as mentioned above. Therefore, it is essential to investigate how blockchain technology can be utilised in the construction industry.

There is a high probability of changing construction project management if the construction industry utilises the blockchain technologies. The success of project management is essential because it is considered as the nerves of construction projects. Concerning that, the involvement of blockchain on project management practices in the construction industry needs to be evaluated. As one of the latest technologies, researchers have focused on the implementation of the blockchain in many industries. Hence this review would be a preliminary study about the applicability of blockchain in the construction industry.

\section{METHODOLOGY}

The literature review can be labelled as a well-established method for an accumulating existing knowledge within a domain of interest. Because of that, as the methodology for this article, it is expected to apply a literature review approach. To find the relevant articles for reviewing, various keywords searches within the ScienceDirect have been proceeded. The publishing period was decided to lie between 2000-2019 to reduce the searching scope. Different keywords such as "blockchain in project management", "blockchain in construction industry", "blockchain in construction", "blockchain and project management practices", "application of blockchain" were used to find relevant articles to choose the topic. However, articles were identified relating to the targeted topic in specific. Therefore, the topics were broadened, and the articles' abstracts were 
carefully read to check their relevance. After reviewing a forty number of articles, the impact of blockchain technology to project management practises were analysed. Project management practises were categorised according to the Project Management Body of Knowledge (PMBOK) guidelines. It was divided into five criterions, namely inventory and asset management, finance and petty cash management, contract administration, subcontractor management and purchases management.

\section{DISCUSSION}

\subsection{BLOCKCHAIN TECHNOLOGY}

Blockchain is made up of blocks, which comprise a number of transactions that chained together by the cryptographic hashes (Gupta, 2018). It consists of three main components namely blocks, blockchain or ledger and network. Selected transactions are stored to a ledger during a given period in a place called block. Those blocks can differ from their objectives, size, period and the triggering event. The blockchain is made up of a number of blocks which are linked together. The tool that links blocks together is cryptographic hash functions (Rodrigo et al., 2018). They are fingerprints of data from the previous block (called as parent block) which links to the current block. Making new block by computing proper hash value is called mining and miners are the people who compete with each other to search the correct hash function (Turk and Klinc, 2017). Further, in the blockchain nodes are interconnected, and each of these nodes holds a complete record of all transaction (Novotny, 2018). Figure 1 illustrates a cryptographically linked blockchain ledger with three blocks.

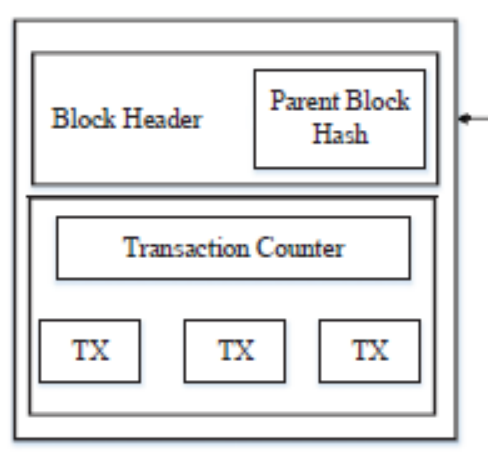

Block i-1

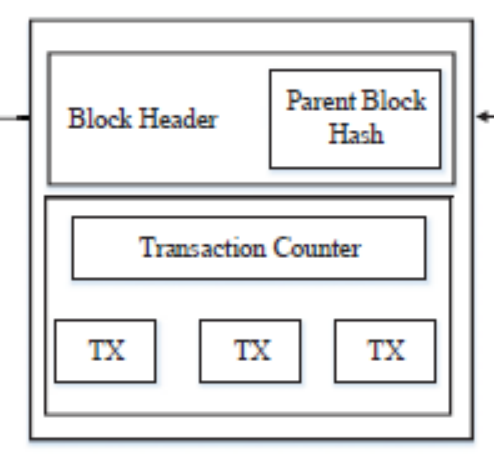

Block i

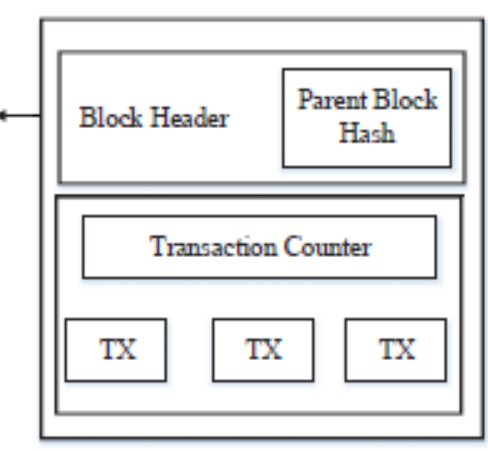

Block i+1

Figure 1: An example of blockchain which consists of continuous sequence blocks

\subsection{BLOCKCHAIN TECHNOLOGY AND CONSTRUCTION INDUSTRY}

Researchers have identified how blockchain technology can be utilised in the construction industry. Novotny and Turk have discussed how blockchain technology can communicate with the delivery of a project along with smart contracts (Novotny, 2018; Turk and Klinc, 2017). According to the McKinsey's point of view, blockchain is capable of handling government policies which need to be fulfilled for the sustainable development (FianderMcCann, 2017). According to the Rothrie (2018), the quality and the accuracy of the surveying data can be enhanced with the blockchain technology as it allows to store a large number of previous records. Abeyratne and Monfared (2016) have researched how blockchain technology can be utilised with project management aspects such as project planning. Likewise, many researchers have expanded their research in many operations 
in the constrcution industry. Following details will provide ellaborated picture about how blockchain technology can be used in the construction industry.

Blockchain and the construction industry are aligned with each other with four basic processes. They are smart contracts, projected modelling, inspection and delivery. The initial step for producing a project is modelling. Project modelling demonstrates how final projects will look like and how needs are accomplished. Once this is completed smart contracts come in to play. For that, each transaction in the project model will be linked with smart contracts. This process will support to make the budget, and it will make ensure that people engaging on the project will be paid. Once the obligations of the contracts are over, they start the works that are scheduled. After the contractor completed his tasks, inspections were done, and approvals or rejections were provided for the tasks completed. If the work is accepted and approved, then the funding will be released, and relevant parties will be paid. After that, the project would be delivered based on the completed works and the payments made. This process provides how blockchain technology can be used throughout the life cycle of the project. It helps to streamline the project delivery and payments so that it would save money by minimising most of the mediators involved in contract processing and payment. Instead of a third party, blockchain permanently stores the transaction record ones it is approved by the participants and this action improves the security and transparency of the transaction. All the data related to the transaction also saved and it will ease the document sharing (Novotny, 2018; Turk and Klinc, 2017).

When it comes to digitalised land acquisition and building rights (when constructing a structure), blockchain solutions show an effective performance. According to FianderMcCann (2017) point of view, blockchain can handle government policies relating to land acquisition and building regulation to have a sustainable construction. Basically, blockchain creates vast advantages over the paper-based activities which allow having quick approvals where it requires multi-party signatures on physical documents. As a good example, the Rajasthan state in India is trying to utilise blockchain technology for their land registration purposes (Rothrie, 2018).

In the construction industry, an inspection of the buildings are done in a fragmented way (Shehu and Akintoye, 2010). Because of this, surveyors do not have details of previous records of the past scrutiny leading to produce bias reports on specific inspectors and cumulative errors. This issue can be prevented using blockchain technologies on building surveying. It makes the opportunity to overlook the past records of a certain building throughout its life cycle (e.g. Structural or maintenance activity) and ensure the corrective activity (Rothrie, 2018).

Planning is another area where blockchain can address in the construction industry. At the current moment, construction organisations have to drag the projects by several months due to improper planning. Together with the Building Information Modelling (BIM) blockchain can make a single source of trust which fulfils all project planning aspects. It will become a trusted twin, which will enhance the predictability of the whole project delivery (Abeyratne and Monfared, 2016).

Further, communication and availability of the information should be significantly improved to move towards smart cities and blockchain-based solutions. For example, sensors data through a public blockchain-based solution can share and utilised to identify the traffic flow in a particular area. Those type of blockchain-based solutions enable quick 
construction investments in road improvements and traffic reassuring measures or other means (Rothrie, 2018).

Blockchain technology will impact construction functions in many ways. Mainly, it influences project management practices of the construction field. As construction projects are based on a pre-defined specification, blockchain combined with smart contract functionalities brings outstanding opportunities to modernise construction project management. It covers whole project lifecycle of construction from initiation to closure and everything in between (Hewavitharana and Perera, 2019). Project Management Body of Knowledge (PMBOK) is the standard guideline, which is followed by project managers to carry on the site operations (Project Management Institute, 2012). According to the writer of project-management.com, Joes Maria De Los Santos, the project manager is the person who gets the heist benefits from the application of blockchain technology to the construction industry as it will result in time-saving, cost removal, and risk reduction (Santos, 2017). Therefore, through this research, it is expected to investigate how blockchain will influence the project management practices mentioned in PMBOK guidelines.

\subsection{Blockchain And Project Management Practises}

\subsubsection{Blockchain and Purchase Management}

Purchase management is a subpart of broad supply chain management. Supply chain management plays a significant role in the construction industry. There are lots of activities from planning to distribution for the clients, and those have to manage in a most streamlined and cost-effective way. The essential element of supply chain management is traceability and communication (Nanayakkara et al., 2015). In construction, it is specified that there are insufficient traceability and communication throughout the supply chain. In the start of 2018, the UK government contract Carillion collapsed affecting the jobs around 43,000 people due to the worthless credit management, lack of prominence over projects and required supplies. Also, still the communication and coordination are handled using telephones, mails and documentation on paper. Therefore, purchase orders, delivery notes and invoices are still operated with papers or centralised software systems. Blockchain technology removes this manual operation system, and it switches all these operations into distributed digitalised form (Sat, 2000; Jang, 2007).

Moreover, blockchain technology impacts to the supply chain management. It helps to do the correct decision making with clear information regarding product and its components. The success of blockchain technology in the supply chain has proven through the partnership between Walmart and IBM (Mancone, 2018). Further, the ProBuild, one of Australia's leading building firm, has joined with US blockchain innovator for developing its global supply chain management though blockchain technology. Also, blockchains based supply chain can track where project assets are at any point in time. Therefore, it built an unbroken chain of trust between all key stakeholders and isolated projects from being document-driven to being data-driven (Hughes, 2017). Moreover, blockchain technology is an effective way to carry out transactions that are stored in decentralised and transparent records. The network itself monitors its security. It can also contain data that monitors costs, labour and wastes at every point in the supply chain (Zheng et al., 2017). The typical structure of a supply chain is shown in Figure 2. 


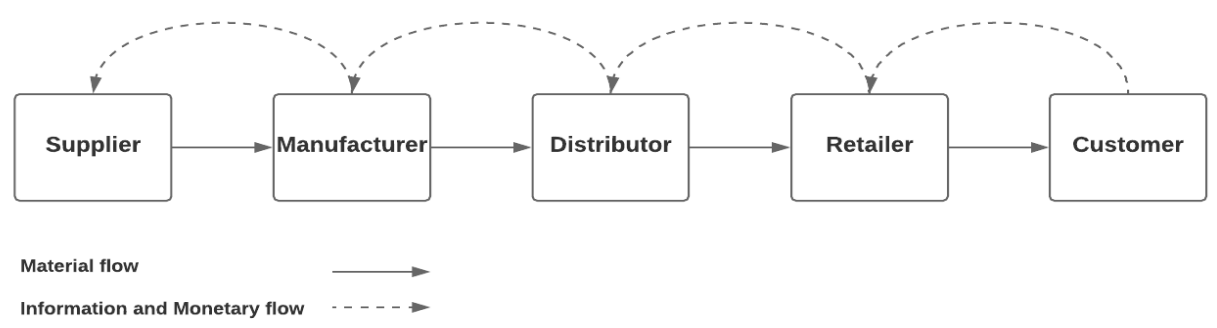

Figure 2: Typical structure of the supply chain

\subsubsection{Blockchain in Asset and Inventory Management}

Construction organizations are unique from other organizations due to its features. Basically, they are project-based entities where the end customers have different preferences and necessities regarding the products (Hewavitharana et al., 2019). Because of this nature, it is necessary to have proper quality control from the starting to the end of the projects. And as it opens up the opportunity to choose their own resources and materials, construction people need to maintain a well-organised supply chain (Perera et al., 2014). By using blockchain technology, authorised parties can certify where materials come from, who are the manufacturers and how they are transported. From that corruption such as child labour, wrong certifications and others can be identified and eliminated.

In the initial stage, barcode systems were used in the inventory management systems, and it was replaced by Radio-frequency Identification (RFID) tagging and Internet of Things (IoT). The blockchain technology can be used to store and properly track the information. "Track Transfer Trust" is one such software which is doing transactions once the work is completed (Abeyratne and Monfared, 2016; Rothrie, 2018).

Further, this could help the purchaser to identify proper suppliers along with the transparency of tracking, material handling at the required time so that construction companies able to operate a "Just in time planning" system, which reduces wastes, lower the cost and accelerate the schedules (Hughes, 2017). Because at the current situation construction firms do not have any clue regarding the inventory control. They do not know whether the supplies they need are in the stock when they start the project. This unplanned situation leads to delay and incur costs (Rothrie, 2018).

Linking the information of BIM into immutable and transparent blockchain will leverage the potential of BIM. Engineering projects contain vast amounts and types of data and similarly high volumes of corresponding design and managerial decisions. Through the blockchain solutions, additional data can be added to the BIM model as well as high accountability and transparency can be ensured due to the irrefutable nature of the ledger. Blockchain can support BIM in two major ways for asset management. It can transfer material requirements, details of other designing as an input to the supply chain management. It also can assign information to the blockchain, like design decisions, a source of data or model modification orders. This information can be used by smart contracts to initiate further actions, such as payments or material orders. One of the main consequences of using blockchain is the introduction of inherent trust within the system. As every system is logged and traceable on the blockchain, many time-consuming, redundant checks can be eliminated. By capturing a comprehensive collection of datasets on the blockchain such as design decisions, content checks, procurement and 
transactional data and linking them to BIM model will enable to identify the origin of the transaction (Shehu and Akintoye, 2010).

Also, the current practice of asset management is constructing its own asset management platform using server-based database. Such practices create issues relating to interoperability specially when there are multiple asset management platforms. This can be sorted out using an Application Programming Interface (API) integrated solution which is connected to a blockchain (Wang et al., 2017).

\subsubsection{Blockchain and Contract Administration}

The initial stage of the construction project is usually much expensive and more significant than other stages as there are inherent risk and fear. Stakeholders often try to mitigate that risk by using proper contract planning and data hoarding. Therefore, blockchains and smart contracts are introduced with the aim of minimising the risk (Hughes, 2017).

A smart contract is a computer program that executes on if/then principle and can execute automatically. Each of these if/then scenarios are recorded on the blockchain. There are two types of smart contracts namely deterministic and non-deterministic. Deterministic contracts only require information exists in the blockchain. As they do not need any outside information, deterministic contracts can execute and work efficiently. Those type of contracts is executed and functioned with the data available within the blockchain. Non-deterministic contracts are smart contracts that need additional information than the available information in the blockchain. For these types of contracts, the trusted third party from outside the blockchain needs to be brought to execute the contracts, and they are called as "Oracles". However, these parties needed to be approved by contractual parties. Oracles are capable of providing smart contracts with the required information (Morabito, 2017).

Moreover, by using smart contracts traditional lump-sum contract and lowest bidder approach can be modified. There are several facts to be considered. As construction companies are operating in a very dynamic environment, it is quite challengeable to trust on the completion of construction projects. For example, with this kind of environment extrinsic and economic incentives such as employees work will be usually overestimated and intrinsic and non-monetary incentives such as social recognition will be underestimated. However, blockchain technology is built upon the trust of fulfilling each operation. Because of this reason though smart contracts are considered as alternatives for the traditional approach, it is advisable to investigate the feasibility of it before the practical implementation (Nanayakkara et al., 2019; Wang et al., 2017).

The investigation has found that smart contracts are cost-effective in many ways. Since the contract is performed entirely in programming languages, unnecessary cost on written text, counselling with lawyers and drafting the contract documents would be avoided. The risk of opportunistic behaviour is also mitigated since the potentially written interpretations of the terms are eliminated. Once one milestone is completed a smart contract is fulfilled and therefore, when the project is scheduled hundreds of smart contracts would be visible to all in Common Data Environment (CDE) (Ramage, 2018). Moreover, smart contracts can replace traditional contracts without the need for laws and courts to a significant extent (Sklaroff, 2018). 


\subsubsection{Blockchain and Finance Management}

In the construction industry, late payments and cash flow issues are enduring problems. The average payment time for construction companies and SME's (Small and Mediumsized Enterprises) became 82 days. They could sometimes even rise as high as up to 120 days. Such practices can easily put the whole supply chain at risk.

Especially the SME's who cannot tolerate the significant upfront costs without continuing payment and healthy cashflow fail to continue a proper supply chain. In 2012 a survey showed that $97 \%$ of 250 SME's experienced unfair, overdue payments. Therefore, it is clear that there is a high need for transparency and tractability of payments in the construction industry. Especially with regard to the fact that there is an increasing trend of managing project funding in public-private partnership which requires more control from the client's side and enhanced accountability from every participant (Ramachandra and Rotimi, 2011).

With the blockchain technology, organisations may able to send money across borders with lower fees in the absence of the middle person. However, it enables virtual currencies such as Bitcoin to be used by the people who even do not have access to traditional banks. In the finance operation, most of the transactions are based upon the authorisation of top management and petty cash handling are depending upon various factors. As there is no involvement of a third party at the transactions, the process is much easier and quicker than the usual way. This process will enhance the productivity of the construction organisation in terms of cash flow handling (Nanayakkara et al., 2019; Turk and Klinc, 2017).

\subsubsection{Blockchain and Subcontractor Management}

The construction industry is unique comparing to other industrial field as it is based on projects which cannot communicate to each other. Subcontractors are the employees who are not permanently involved in the projects. Mostly, they are handled by main contractors as they can perform specific tasks. As there are several types of subcontractors within one project, project managers face lots of difficulties with measuring the work done and the interim payments (Ramachandra and Rotimi, 2011). This problem can be solved by the implementation of blockchain solutions. The subcontractors' works can be linked to the blockchain associated with payments and verifiable milestones. Each of these verifiable elements will be presented on the BIM model, and once it has completed, it will be recorded in blockchain ledger (Ramage, 2018). As an example, once the transactions are connected with blockchain technology all orders, deliveries and invoicing could able to handle by smart contracts. Then the payments could be linked with contracts automatic payments. This approach prevents the involvement of the third party and streamlines faster payments.

\section{CONCLUSIONS}

Through this literature review, it is identified that blockchain technology can influence construction project management practices. In here, five basic functionalities in the project management area were addressed namely a) Contract administration, b) Purchase management (supply chain management), c) Subcontractor management, d) Finance management and e) Asset and inventory management. 
It will maintain the security and trust between all parties and will able to monitor costs, schedules, labour, waste and others at many points of the supply chain. If the blockchain technology is used in financial management, it will speed up the payments without involving third parties and eliminate long term delays in the cash flow. The subcontractors' work can be related to the blockchain technology associated with payments and verifiable deliverable milestones. Smart contracts could build for each and every work done item; once the work is done completed orders, deliveries and invoicing will be linked to the payment. This will improve the efficiency and the productivity of the subcontractor handling. Blockchain technology supports material and asset management by tracking and tracing material movements. Further, it will enable just in purchasing systems and will eliminate unnecessary storage cost, maintenance cost and reduce wastage.

Therefore, it is identified that blockchain would impact traditional construction practices and bridge the future while creating the best project management tool for the construction industry.

\section{REFERENCES}

Abeyratne, S.A. and Monfared, R.P., 2016. Blockchain ready manufacturing supply chain using distributed ledger. International Journal of Research in Engineering and Technology, 05(09), pp.1-10.

Fiander-McCann, D. 2017. Blockchain could transform the construction industry - Designing Buildings Wiki [Online]. Designing Buildings Wiki. Available: https://www.designingbuildings.co.uk/wiki/Blockchain_could_transform_the_construction_industry [Accessed 2018-01-29 2018].

Gupta, M., 2018. Blockchain for Dummies, 51, $2^{\text {nd }}$ edn, pp. 3-10. Hoboken, NY: Wiley.

Hewavitharana, T., Nanayakkara, S., Perera, A. and Perera, J. 2019. Impact of Enterprise Resource Planning (ERP) Systems to the Construction Industry. International Journal of Research in Electronics and Computer Engineering, 7, pp.887-893.

Hewavitharana, T. and Perera, A. 2019. Gap Analysis between ERP procedures and Construction procedures. MATEC Web of Conferences. Kuala Lumpur, Malaysia: Web of Conferences.

Hughes, D. 2017. The Impact of Blockchain Technology on the Construction Industry. animal Media.

Jang, W. S. 2007. Embedded system for construction material tracking using combination of radio frequency and ultrasound signal (Doctoral Thesis).

Mancone, R. 2018. Blockchain Services and Strategy, IBM.

Morabito, V., 2017. Business innovation through blockchain. Cham: Springer International Publishing.

Nanayakkara, S., Perera, P. and Perera, A. 2015. Factors Incompatibility of Selection and Implementation of ERP Systems for Construction Organizations. International Journal of Computer Science and Technology, 6, pp.9-15.

Nanayakkara, S., Perera, S. and Senaratne, S. 2019. Stakeholders' Perspective on Blockchain and Smart Contracts Solutions for Construction Supply Chains. CIB World Building Congress. Hong Kong.

Novotny, R. 2018. Blockchain and the Construction Industry: Hype or an Industry Innovation? - eSUB Construction Software.

Perera, P., Nanayakkara, S. and Perera, A. 2014. Application of Proper Asset Management Methodology and Technology. International Journal of Computer Science and Technology, 5, pp.33-41.

Project Management Institute 2012. A Guide to the Project Management Body of Knowledge, USA, Project Management Institute.

Ramachandra, T. and Rotimi, J. O. 2011. The nature of payment problems in the New Zealand construction industry. Australasian Journal of Construction Economics and Building, 11, pp.22-33.

Ramage, M., 2018. From BIM to Blockchain in Construction: What You Need to Know. Trimble Inc. 
Rodrigo, M. N. N., Perera, S., Senaratne, S. and Jin, X. 2018. Blockchain for Construction Supply Chains: A literature Synthesis. Proceedings of ICEC-PAQS Conference 2018. Sydney, Australia.

Rothrie, S. 2018. How Blockchain and Construction Will Build a New World [Online]. Coin Central. Available from: https://coincentral.com/blockchain-and-construction [Accessed 2018-01-18 2018].

Santos, J. M. D. 2017. Blockchain as a Project Management Platform. PM.com.

Sat, T. 2000. A Design Method. Production Economics, 64, pp.92-95.

Shehu, Z. and Akintoye, A. 2010. Major challenges to the successful implementation and practice of programme management in the construction environment: A critical analysis. International Journal of Project Management, 28, pp.26-39.

Turk, Ž. and Klinc, R. 2017. Potentials of Blockchain Technology for Construction Management. Procedia Engineering, 196, pp.638-645.

Wang, J., Wu, P., Wang, X. and Shou, W. 2017. The outlook of blockchain technology for construction engineering management. Frontiers of Engineering Management, 4, pp.67-75.

Zheng, Z., Xie, S., Dai, H., Chen, X. and Wang, H., 2017. An overview of blockchain technology: Architecture, consensus, and future trends. 2017 IEEE International Congress on Big Data (BigData Congress), 2017. IEEE, pp.557-564. 